\title{
A Structural Modelling Approach to Predict Adolescent Offending Behaviour from Family, School and Community Factors
}

\author{
Estefanía Estévez • Nicholas P. Emler
}

(C) Springer Science+Business Media B.V. 2010

\begin{abstract}
It seems undeniable that immediate social contexts exert an important influential role on adolescent behavioural adjustment. Research thus far has found that certain family, school and community/neighbourhood environment characteristics may influence a youth's involvement in risk activities such as antisocial behaviour and drug use, and even delinquent behaviour. However, the mechanisms that link these characteristics to such behaviours have not yet been thoroughly analysed and prior research has focused mainly on adult populations. The objective of this study was to analyse the joint contribution of specific factors, deriving from family, school and society, which have an effect on levels of drug consumption, antisocial and offending behaviour, in a sample of 2528 youths (aged 10 to 16). In particular, in accounting for involvement in risk activities and ultimately in offending behaviour, we examined interactions among the following variables: living in a disadvantaged community, quality of relationship with parents, distrust in local police, attitude to social norms, and rejection of and from school (truancy, suspension and expulsion). A structural equation model was calculated to account for these interactions, which revealed patterns of influence with important practical implications related to social policies on risk behaviours in adolescence.
\end{abstract}

Keywords Adolescence - Antisocial behaviour - Drug use · Family · Offending behaviour . School

E. Estévez

Universidad Miguel Hernández de Elche, Alicante, Spain

N. P. Emler

University of Surrey, Guildford, Surrey, United Kingdom

E. Estévez $(\bowtie)$

Departamento de Psicología de la Salud, Universidad Miguel Hernández de Elche, Avenida Universidad, s/n, Edificio Altamira, 03202 Elche, Alicante, Spain

e-mail: eestevez@umh.es 
In recent years, research on adolescent behavioural adjustment and the development of deviant behaviour has shown that conditions found at individual, family, school and community level, as well as their interactions, can influence the probability of involvement in risk activities and practices (McCord et al. 2001). It has been argued that the more risk factors present, the higher the probability of involvement in offending behaviour. However, it is also true that not all adolescents reach adulthood with serious behavioural problems even if in they have had to live in conditions which present multiple risks. Hence, the understanding of how such factors interact is essential when examining the level of influence they have on adolescent behaviour. In the present study we focus on the joint contribution of specific factors, deriving from family, school and community environments respectively, with the intention of explaining adolescents' involvement in risk activities, namely drug use, deviant and/or delinquent behaviour. Correlations between these three antisocial activities are also examined.

Research suggests that taking part in antisocial activities and drug consumption may subsequently lead to offending behaviour behaviour. Regarding antisocial behaviour, and following Moffitt $(1993,2006)$, at this point it is necessary to differentiate between adolescence-limited antisocial behaviour and life-course-persistent antisocial behaviour. Thus, for some adolescents, behaving in an antisocial manner is considered to be temporary and situational. Although, for a minority of adolescents antisocial behaviour is considered to be a constant and may consequently persist into adulthood. In particular, with regard to behavioural problems, the latter group seems to show a certain amount of continuity and escalation, that is to say, a progression from minor to more serious and ultimately criminal misbehaviour (Pudney 2002). Minor offences consist in antisocial acts, typically defined as acts that disturb the peace and disrupt the social order and that "are likely to cause harassment, alarm or distress to members of the public not of the same household as the perpetrator" (Crime and Disorder Act, 1998, UK). Such behaviour may lead to less trivial acts more clearly falling within the definition of crime, such as shoplifting. In fact, recent studies indicate that theft (including shoplifting) is the prevalent initial crime and the most common offence committed by adolescents (Barry 2006; Cunneen and White 2002; Rutter et al. 1998). In the longitudinal study conducted by Wiesner et al. (2005), the authors point out that early involvement in antisocial behaviour reduces an individual's opportunities to engage in other kinds of positive interactions and activities. Consequently the individual is trapped in a risky and dangerous lifestyle, which in part may explain the link between antisocial and delinquent behaviour.

The correlation between drug consumption, antisocial behaviour and delinquency has also been analysed in studies which examined adolescent samples. In recent years greater attention is being paid to the correlation between such types of deviant behaviour in response to an evident increase in drug consumption among young offenders (Copeland et al. 2003; Lennings et al. 2003). There is also an on-going debate as to whether drug users are more inclined to behave in a deviant manner or vice versa (Pudney 2002). The psycho-pharmacological effects brought on by certain substances, along with the need for money arising from drug dependence, may lead to antisocial and/ or delinquent behaviour (Goldstein 1989); moreover these tendencies have been found to have long-term effects, reaching into early adulthood (Brook et al. 1996; Lennings et al. 2003).

Research also shows, however, that behaving in an antisocial and/or delinquent manner can lead to experimentation with drugs, given that antisocial behaviour weakens adherence to authority and established social norms, thus increasing openness 
to other risk behaviours such as drug consumption (Chaiken and Chaiken 1990; Wiesner et al. 2005). Long-term effects have also been verified in longitudinal studies which have found that early delinquent behaviour is linked to drug consumption in later years (Pedersen et al. 2001; Reebye et al. 1995; Robins and McEvoy 1990). In a recent study, Wei et al. (2004) found a bidirectional correlation between delinquency and the consumption of alcohol and cannabis in adolescents. The authors concluded that delinquency, together with alcohol and/or drug consumption are influenced by common risk factors.

Some common factors which significantly influence adolescents' behaviour, especially with regard deviant doings, have been identified. These influential factors are often linked to the individual's immediate social contexts, namely family, school and the local community in which the young person lives. Starting with the latter, neighbourhoods can influence youths' behaviour by providing them with examples of social values. In turn these examples shape youths' perceptions of what is considered acceptable social behaviour (McCord et al. 2001). Thus, communities in which deviant acts and crimes are common may exert a strong impact on how youths interpret and internalise the local social norms. This is a fact which is significantly correlated to the degree of adhesion to and respect for the community's social norms and values (Proctor 2006; Scarpa and Haden 2006; Webster et al. 2006).

There is also a small body of literature which suggests that the perception of general neighbourhood conditions influences attitudes towards police and the mainstream justice system. It is suggested that this is especially true where negative conditions may be associated with the operations and efforts employed by official state authorities (Christenson and Taylor 1983; Stipak 1979; Weitzer and Tuch 2004). It is to be noted, however, that the vast majority of studies carried out so far focus mainly on adult populations; much less is known about the correlation between adolescents living in disadvantaged communities and their attitudes towards official state authorities. One study, conducted in the United States by Hurst and Frank (2000) and which focused on juveniles, revealed that those who believed that the conditions in the communities where they resided were worse than in other communities tended to blame the state authorities for their community's breakdown, claiming that the authorities did not employ as much effort in enforcing order in these communities. As a result a less favourable attitude towards the police was generally expressed by the people residing in these communities. These findings become even more significant if we take into account the close correlation between attitudes towards authorities, antisocial behaviour and offending behaviour during adolescence (Emler and Reicher 1995, 2005; Musitu et al. 2007; Loeber 1996; Tarry and Emler 2007). In fact, it appears that attitude towards law enforcement agencies is a key factor in explaining level of respect for and conformity to social norms (Jesen 1969; Tyler and Hou 2002; Tyler 2006).

There are now several studies confirming the strong correlation between attitudes towards various agencies of state authority such as the police, law enforcement agencies, schools and school teachers (Emler et al. 1990; Emler et al. 1987; Levy 2001; Molpeceres et al. 1999; Rubini and Palmonari 1998). Attention should be paid to such associations additionally because attitudes towards school have been found to be significantly correlated with deviant behaviour in adolescence. According to Hirschi (1969), adolescents who show a strong attachment and commitment to school are less likely to engage in deviant activities than youths showing weaker bonds. Subsequent studies of adolescents from different cultural backgrounds have supported these conclusions, demonstrating that these two factors are negatively correlated with antisocial behaviour (Leblanc 1994; Moncher and 
Miller 1999; Thornberry et al. 1991). These conclusions are also in line with the findings of Carroll et al. (2001, 1999), which show that delinquent and educational goals appear to be opposed.

A low level of commitment and a negative attitude to school, together with a lack of educational goals, are closely related to truancy. Additionally, in many schools, deviant behaviour can eventually lead to suspension from school or even expulsion, both of which are disciplinary measures implemented to counteract deviant behaviour. Even though plenty of research has been carried out on the demographic profile of truanting, suspended, and expelled students, empirical evidence related to the effects caused by their behaviour and studies of their participation in acts which involve risky behaviour are much more limited (McAra 2004; Rutter et al. 1998). The few recent studies which focused on these issues show that, contrary to common belief, suspension and expulsion from school are actually strong predictors of engagement in risk activities, which may include both antisocial behaviour and drug consumption, and hence such disciplinary measures do not moderate misbehaviour as intended (McAra 2004; McAra and McVie 2007; Smith 2006). The same pattern has been found with respect to truancy, which is consistent with the fact that characteristics associated with adolescents who regularly truant are similar to those related to adolescents who are suspended and expelled from school (McCord et al. 2001). It has been suggested that one of the causes of higher levels of offending among these students is related to the greater amount of time they spend primarily on the streets and without adequate supervision (Arum and Beattie 1999).

Finally, current literature reveals a significant correlation between adolescents' involvement in risk behaviours and certain characteristics within the family environment. Thus, problems related to a lack of communication or inadequate expression of acceptance and understanding, a lack of affective cohesion and parental support, together with parental discipline based on excessive permissive or authoritarian control versus adequate monitoring, have all been found to be significantly correlated with antisocial behaviour and delinquency (Barrera and Li 1996; Baumrind 1978, 1991; Demaray and Malecki 2002; Musitu et al. 2007). Such deviant behaviour may also include alcohol and drug consumption among adolescents (Barnes and Farrell 1992; Butters 2002; Denton and Kampfe 1994).

Considering these findings, it seems undeniable that immediate social contexts have a significant influence on adolescent behavioural adjustment. Nevertheless, it should be noted that even though research thus far shows that certain community and neighbourhood characteristics, along with school and family environments, may significantly influence adolescents' involvement in risk activities, the mechanisms which link these factors and influence processes have not been thoroughly analysed and in previous studies the populations analysed consisted primarily of adults. The objective of this study was, therefore, to analyse the joint contribution of specific factors found within the family, school and community and the effects they have on levels of drug consumption, antisocial behaviour and offending behaviour among a sample of young people in their first years of adolescence. More specifically, in accounting for involvement in risk activities and ultimately in acts of delinquency, we examined interactions between the following variables: living in a disadvantaged community, quality of relationship with parents, distrust in local police, attitude to mainstream social norms, and rejection of and from school (truancy, suspension and expulsion).

We hypothesised that there would be indirect links between, on the one hand, community, school and family factors and, on the other, offending behaviour in adolescents. We hypothesised that such relationships are mediated by attitudes towards social norms, 
antisocial behaviour and drug consumption. More specifically, we expected the following interrelations among variables: (1) Perception of living in a disadvantaged local area would be associated with partaking in antisocial behaviours; (2) Perception of negative conditions in the neighbourhood of residence would be associated with a lack of trust in the local police, as well as with negative attitudes to mainstream social norms; (3) A negative relationship between parent and adolescent would be associated with a negative attitude towards other official law enforcement agencies (i.e. police); (4) Rejection of and from school (truancy, suspension and expulsion) would be associated with a higher probability of involvement in risk activities such as antisocial behaviour and drug consumption; (5) A negative attitude towards social norms would show a direct correlation with risk activities; and (6) Participating in deviant activities and drug consumption would show a bidirectional association, while both forms of behaviour would be directly related to offending behaviour.

\section{Method}

Sample

The analyses were based on data from the 2005 Offending Crime and Justice Survey (OCJS), which was jointly designed and carried out by the Home Office, the National Centre for Social Research (NatCen) and the British Market Research Bureau (BMRB). The 2005 OCJS sample is a nationally representative sample of young residents in general households in England and Wales. A total of 2528 participants (52\% boys and $48 \%$ girls) in the early and middle adolescence-aged from 10 to 16 years old-were randomly selected and interviewed.

\section{Procedure}

An original multi-staged stratified random sample was used to recruit participants. Thus, addresses were randomly selected from the postcode address file and respondents were chosen by their age to take part in the study. All participants were interviewed by interviewers employed by NatCen and BMRB in the respondent's home from January to October 2005. Interviews were carried out using a laptop computer and three separate computer-assisted modes: (1) Computer Assisted Personal Interviewing (CAPI) was used in the first part of the interview face to face with the interviewer reading the questions from the computer screen and imputing the answers. (2) Computer Assisted Self Interviewing (CASI) was used in the second part of the interview for more sensitive questions. Here interviewees entered their own responses directly in the manner of a self-completion survey, (3) Audio-CASI was used for questions referring to antisocial behaviour and offending behaviour; here, in addition to the questions and response codes appearing on the screen, respondents could listen to them through headphones, thus assisting participants with literacy problems. Further details about the OCJS and published reports can be accessed at: http://www.homeoffice.gov.uk/rds/offending_survey.html

\section{Measures}

For the present study the following measures were used: perceived problems in the local area, relationship with parents, trust in local police, attitude to mainstream social norms, 
rejection of and from school, antisocial behaviour, alcohol and drug use, and offending behaviour. All measures were coded so that a higher score represented a more negative perception or attitude or more frequent involvement in that behaviour.

To obtain a measure of perception of disadvantaged local area, participants indicated if the following nine problems were common in their neighbourhoods: noisy neighbours, teenagers hanging around causing problems, people sleeping rough on the streets or in other public places, people being harassed in the streets, people using or selling drugs, people being drunk or rowdy in public, rubbish or litter lying around, abandoned or burnt our cars, people begging at cash points or other places. A general measure was created in the present study by summing across the nine items which were coded $0=$ no and $1=$ yes.

To assess relationship with parents, adolescents were asked if the following four statements referring to family support, communication and monitoring, were true for them and coded as $0=$ yes and $1=$ no: My parents usually praise me when I have done well (for example, at school or playing sport), my parents usually listen to me when I want to talk, my parents usually treat me fairly when I have done something wrong, and my parents usually want to know where I am when I am not at home.

Respondents were asked how much they trusted in police in their local area, answers coded as: 1 = a lot, $2=$ a fair amount, $3=$ not very much, and $4=$ not at all. They also indicated to what extend they agreed or disagreed with the following four statements, responses being combined into a measure of attitude to mainstream social norms: (1) it is okay to steal something if you are very poor; (2) it is okay to steal something from somebody rich who can afford to replace it; (3) it is okay to steal something from a shop that makes a lot of money; (4) it is sometimes okay to break the law. Answers were coded as $1=$ strongly disagree, $2=$ disagree, $3=$ neither agree nor disagree, $4=$ agree, and $5=$ strongly agree.

Rejection of and from School This measure was based on responses to questions asking whether the participant had been expelled from school, had been suspended from school for a limited period of time, and had played truant frequently in the last year. Responses were coded as $0=$ no and $1=$ yes. Responses to the three questions were combined for each respondent. Antisocial behaviour was assessed with four items asking whether respondents had been involved in each activity described in the last 12 months $(0=$ no, 1 = yes). Questions referred to: having been noisy or rude in a public place so that someone complained; writing things or spraying paint on a building, fence, train or anywhere else where it is not allowed; threatening or having been rude to someone because of their skin colour, race or religion; annoying neighbours by the respondent's behaviour.

Alcohol use was assessed by asking respondents how often they had felt drunk in the last year, and coded as follows: $1=$ less than once every two months, $2=$ once every two months, $3=$ once a month, $4=$ twice or three times a month, $5=$ once or twice a week, and $6=$ most days. For drug use the three types of drugs most often consumed by adolescents in the present sample were considered (used in the last 12 months): glue-solvents, amyl nitrites (poppers); cannabis.

The measure of Offending behaviour covered 20 different offences referring to both personal and property offending activities. Personal offences referred to: personal robbery, theft from a person, assault resulting in injury and assault without injury. Property offences referred to several vehicle-related thefts and criminal damage (e.g., theft of parts from the outside of a vehicle, theft of items inside a vehicle, criminal damage to a vehicle), burglary 
of dwellings or commercial premises, other thefts (e.g., from the school, shop) and offences related to drug selling.

\section{Results}

We used AMOS software version 6.0. (Arbuckle 2005) of the SPSS program (SPSS, 2005) to analyse, by means of a structural equation model, patterns of interaction among variables. Preliminary correlational analyses among all observable variables included in the structural model were carried out (see Table 1) as a first step in examining their interrelations. All correlations were statistically significant at $\mathrm{p}<.01$ and particularly strong between offending behaviour and rejection of and from school (expulsion, suspension and truancy), involvement in antisocial behaviour and alcohol and other drugs use.

Figure 1 shows the structural model tested with the standardised path coefficients showing a significant level of .001 and regression weights higher than .10. Regarding goodness of fit, for the chi-square likelihood-ratio statistics, a non-significant value indicates that the model provides a good fit with the data; however, since $\chi^{2}$ is very sensitive to large sample sizes, as in this case, other fit indexes must be considered. Several indexes of fit were examined in the current study, including the comparative fit index or CFI, the incremental fit index or IFI, the Bentler-Bonett normed fit index or NNFI, and the root mean square error of approximation or RMSEA. All these fit indexes are frequently used as adjuncts to chi-square statistics for evaluating the fit of a structural model. Their values are given by the statistical programs designed to calculate structural equations. Some authors propose that values above .90 or higher for the CFI, IFI and NNFI and values of .08 or less for the RMSEA are acceptable (Arbuckle 2005; Browne and Cudeck 1993), while others recommend more conservative values such as .95 for the CFI, IFI, and NNFI and .05 for the RMSEA (Batista and Coenders 2000; Bentler and Wu 2002).

The model calculated provided a good fit with the data, with one exception exceeding the more conservative values recommended: $\chi 2(16, \mathrm{~N}=2528)=91.655$ $(\mathrm{p}<.000), \mathrm{CFI}=.98, \mathrm{IFI}=.98, \mathrm{NFI}=.97$, and RMSEA $=.04$, and accounted for $53 \%$ of the explained variance in the outcome variable Offending Behaviour. This model is composed

Table 1 Pearson correlations among observable variables in the structural model

\begin{tabular}{|c|c|c|c|c|c|c|c|c|c|}
\hline Variable & 1 & 2 & 3 & 4 & 5 & 6 & 7 & 8 & 9 \\
\hline 1. Disadvantaged area & - & & & & & & & & \\
\hline 2. Poor relation parents & $.15^{* *}$ & - & & & & & & & \\
\hline 3. Distrust in police & $.24 * *$ & $.15^{* *}$ & - & & & & & & \\
\hline 4. Neg. attitude social norms & $.10 * *$ & $.10 * *$ & $.13 * *$ & - & & & & & \\
\hline 5. Rejection school & $.20 * *$ & $.15^{* *}$ & $.23 * *$ & $.11 * *$ & - & & & & \\
\hline 6. Antisocial behaviour & $.23 * *$ & $.16^{* *}$ & $.25 * *$ & $.23 * *$ & $.27 * *$ & - & & & \\
\hline 7. Alcohol use & $.12 * *$ & $.13 * *$ & $.14 * *$ & $.12 * *$ & $.26 * *$ & $.32 * *$ & - & & \\
\hline 8. Drug use & $.11^{* *}$ & $.15^{* *}$ & $.13^{* *}$ & $.17 * *$ & $.28 * *$ & $.32 * *$ & $.46^{* *}$ & - & \\
\hline 9. Personal offences & $.17 * *$ & $.14 * *$ & $.13 * *$ & $.15^{* *}$ & $.20 * *$ & $.37 * *$ & $.15^{* *}$ & $.15^{* *}$ & - \\
\hline 10. Property offences & $.12 * *$ & $.17 * *$ & $.17 * *$ & $.22 * *$ & $.36^{* *}$ & $.52 * *$ & $.29 * *$ & $.37 * *$ & $.43 * *$ \\
\hline
\end{tabular}

Level of significance: $* * p<.01$ 


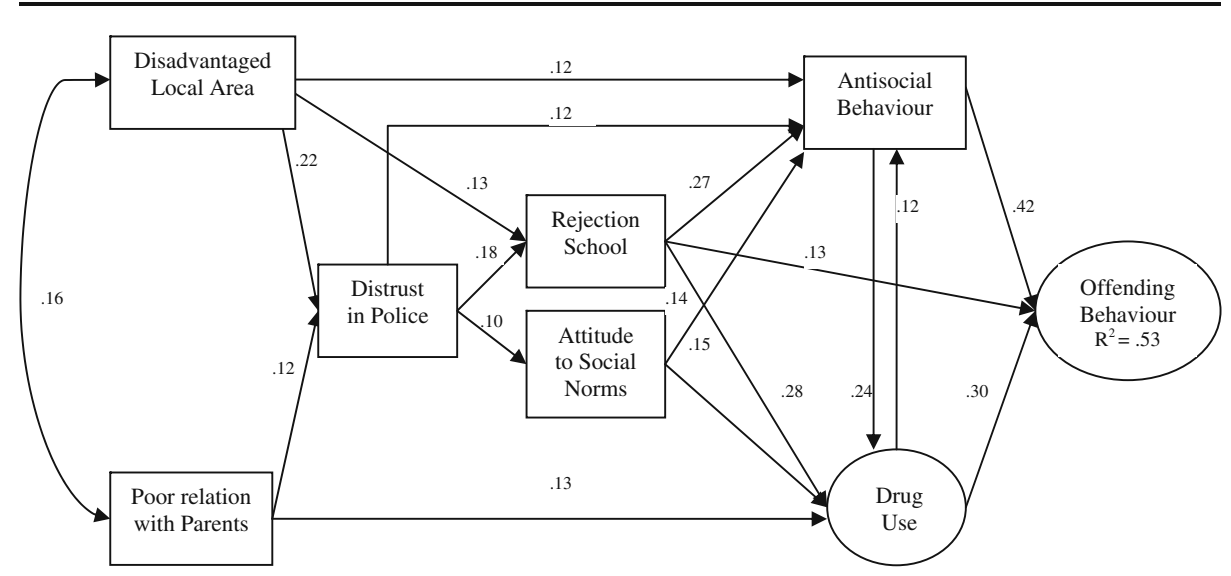

Fig. 1 Structural equation model to predict offending behaviour in adolescence ${ }^{1}$. ${ }^{1}$ Continuous lines represent significant paths among observable variables (squares) and latent factors (circles). The curve line represents a correlation. Robust standard errors were used to determine the significance of the standardized paths. All standardized regression weights are shown above the correspondent arrow and are significant at $\mathrm{p}<.001$ level

of six observable variables represented by squares in the figure and two latent factors represented by circles. Latent factors were Drug use, with two indicators: alcohol use (factor loading fixed to 1 during estimation by the program) and other drugs use (standardised factor loading .70, standard error .15); and Offending behaviour, with two indicators: personal offences (factor loading fixed to 1 during estimation by the program) and property offences (standardised factor loading .82, standard error.02). The remainder of the variables in the model consisted of only one indicator and, therefore, their factor loadings were 1 with an error 0 . The model also showed correlated errors between living in a disadvantaged area and poor relations with parents $(\mathrm{r}=.16)$.

As results in Fig. 1 suggest, negative perception of the immediate social and family context, or in other words, the fact of perceiving the local area as disadvantaged on the one hand, and having poor quality relations with parents on the other hand, are both influential factors related to the subsequent development of particular attitudes towards other institutional figures and bodies, namely the school, the police and the law, each of them in turn related to involvement in risk activities such as antisocial behaviours and the use of drugs, both being at the same time strong predictors of offending behaviour.

The structural model revealed three main significant direct paths of influence to offending behaviour: antisocial behaviour, which showed the strongest association $(\beta=.42$, $\mathrm{p}<.001)$, followed by drug use $(\beta=.30, \mathrm{p}<.001)$ and rejection of and from school $(\beta=.13$, $\mathrm{p}<.001)$. This latter showed both direct links with offending behaviour and indirect links through its simultaneous influence on antisocial behaviour $(\beta=.27, p<.001)$ and the use of drugs $(\beta=.28, \mathrm{p}<.001)$. Another factor that exerted a direct impact on both antisocial behaviour and drug use was attitude to social norms $(\beta=.14, p<.001$ and $\beta=.15, p<.001$ respectively). Moreover, antisocial behaviour and drug use revealed a bidirectional association, being both influenced by and influencing each other (antisocial $\rightarrow$ drug use $\beta=.24, \mathrm{p}<.001$; drug use $\rightarrow$ antisocial $\beta=.12, \mathrm{p}<.001$ ), although the path from antisocial behaviour to drug use had a higher regression coefficient than vice versa.

Other factors showing direct and indirect relationships with antisocial behaviour and drug use and thus indirectly influencing involvement in offending behaviour were living in an area of perceived disadvantage and having poor relations with parents. A significant 
direct association was found between living in a disadvantaged community and antisocial behaviour $(\beta=.12, \mathrm{p}<.001)$; the link between these two factors was also established through the influence of living in a problematic area on distrust in police (problematic area and distrust in police $\beta=.22, \mathrm{p}<.001$; distrust in police and antisocial behaviour $\beta=.12, \mathrm{p}<.001$ ) and on rejection to and from school (problematic area and rejection school $\beta=.13, \mathrm{p}<.001$ ). Also poor relations with parents directly influenced drug use $(\beta=.13, \mathrm{p}<.001)$ and distrust in police $(\beta=.12, p<.001)$. And distrust in police was in turn related to rejection to and from school $(\beta=.18, \mathrm{p}<.001)$ and attitude to social norms $(\beta=.10, \mathrm{p}<.001)$.

\section{Discussion}

The present study has examined, by means of a structural equation model, patterns of interaction and influence among family, school and community factors associated with involvement in risk activities in adolescence and, ultimately, with offending behaviour. As a whole, our results indicated that adolescent's perception of characteristics of community and family contexts influence the shape of their attitudes towards institutional bodies and their representatives, namely the police, the school and the law, while these attitudes are in turn closely related to participation in risky activities - drug and alcohol use, antisocial behaviour, offences against property and persons - in this period of life. Our findings suggest, moreover, a link between characteristics of the community and the family, since they were significantly correlated, indicating that not only do each of them make a unique contribution to adolescent attitudes and behaviour, but also a joint contribution. Indeed, prior studies have stressed that features of local area seem to interact with family characteristics. Thus, it has been found that parental guidance may exert a protective effect with respect to antisocial behaviour regardless of neighbourhood but that, conversely, poor family socialisation practices have a stronger negative impact on children's behaviour in disrupted communities (McCord et al. 2001). Interrelation of both social contexts must be therefore considered if we are to understand certain adjustment problems in adolescence.

Analysing relationships in the model in more depth, we found firstly some indirect paths of influence of perception of a disadvantaged local area on engagement in offending behaviour. On the one hand, in accordance with our first hypothesis and in line with recent previous research (Proctor 2006; Sampson 2004a, b; Scarpa and Haden 2006), perception that one lives in a disadvantaged community increases the likelihood of committing antisocial acts. This result is consistent with the "broken windows" theory based on the proposition that if a window in a particular neighbourhood is broken and is left unrepaired, all the other windows will probably soon be smashed as well (Wilson and Kelling 1982). Informal rules enforced by residents help to provide good order in a neighbourhood; however, if the area is uncared for and negatively perceived, antisocial behaviour will be more frequent and commonplace among its inhabitants, a fact that in turn constitutes a risk factor for youth's involvement in more serious offences, as our results indicate.

On the other hand, and as anticipated in the second hypothesis, living in a disadvantaged area seems also to exert an indirect influence on young residents' offending behaviour through its impact on perceptions and attitudes related to social norms and formal institutions. In particular, our analysis suggested that a negative perception of the local area is related to distrust in local police and rejection of and from school, and that these two are in their turn linked to antisocial behaviour. Research with adults had previously shown a link between negative neighbourhood conditions and negative attitude towards police (Christenson and Taylor 1983; Stipak 1979; Weitzer and Tuch 2004). A study by Hurst and 
Frank (2000) in the United States indicates this association also holds among juveniles. The present analysis therefore is in line with their findings with a sample of western European adolescents, suggesting that communities in which antisocial acts and crimes are common make an impression on adolescents' confidence in police with subsequent negative consequences. One of these consequences may be that, as indicated in the model, distrust in police regarding enforcement of law and care of the community as well as protection of citizens, adversely affects children's understanding of, internalisation of and support for established social norms, which constitute in turn significant antecedents to participation in risk activities such as antisocial behaviour and also drug use, both strong predictors of offending behaviour. Although this influence process has not yet been analysed in depth in the adolescent population, it is clear from previous studies that attitude to formal authorities, such as police and the law is closely related not only to antisocial behaviour but also to offending in adolescence (Emler and Reicher 1995, 2005; Estévez et al. 2007; Loeber 1996; Tarry and Emler 2007).

This link between attitude to authority and degree of respect for mainstream social norms can be applied not only to police as a formal authority but also to school as a formal institution and even to parents as informal authority figures. Indeed, and as indicated in the third hypothesis, the model showed a close association between holding negative relations with parents, distrust in police and rejection of and by school. Although this result is consistent with prior studies showing the high correlation between attitudes towards different authority figures and institutions such as parents, police and teachers and especially between the two latter in adolescence (Molpeceres et al. 1999; Murray and Thompson 1985), research has hitherto failed to explain how particular perceptions of one authority figure shapes perceptions of another. It seems reasonable, however, to propose that quality of interactions among family members will shape the perception of parents as models of authority, a perception that may be generalised to other authorities that are encountered later in life, such as teachers and police officers, and formal institutions such as the school and the wider legal system.

Thus, and also in line with our findings, it has been documented that a negative perception of, and lack of attachment and commitment to, school is translated in many cases into truancy and misbehaviours at school (Hirschi 1969), both frequently translated into the punishment measures of temporarily suspension and longer term exclusion from the educational setting. Our results suggested, in accordance with the fourth hypothesis, that these two school policies, usually understood as disciplinary techniques, may contribute to negative outcomes in high risk adolescents, such as antisocial behaviour and drug use, being both in turn strong predictors of offending. This finding is consistent with those reported by McCord and colleagues in the United States (2001) who stress that suspension and expulsion have social and academic effects that are clearly detrimental. They make it difficult for adolescents to keep up with academic subjects while giving them additional time without supervision, which leads to a risk situation for engaging in misbehaviours and offending (Arum and Beattie 1999).

At this point it is important to note the link between conditions in the local area and commitment to or rejection by and of school, since these two factors also showed a significant relationship in the model, which had not been considered in our initial hypotheses. It seems then that young people living in disadvantage neighbourhoods are less likely to be fully engaged with formal education and more prone to truancy. What is key here is how that time is then spent and with whom (Webster et al. 2006). Social relationships formed during truancy and particularly in association with a "street youth culture" can constitute a significant risk factor for offending (MacDonald and Marsh 2005). Thus, suspension and expulsion increase chances of coming into contact with a delinquent subculture, setting up a vicious negative 
cycle of effects on schoolwork together with the stigma associated with those practices once the child returns to school (Williams 1989). Moreover, these practices -suspension and exclusion- do not modify the misbehaviour as they were designed to do, since rates of recidivism remain high among these students (McFadden et al. 1992).

To sum up, our findings indicate that, as a whole, offending behaviour in adolescence is closely related to rejection to and from school, antisocial behaviour and drug use. These three latter factors, as expected in the fifth and sixth hypotheses, showed direct associations with offending and in turn were predicted by negative perceptions of the community and family contexts as well as the mainstream social norms and authorities. Drug use, as an antecedent of offending was, moreover, influenced by quality of relations with parents and negative perception of mainstream social norms. On the one hand, problems of family communication, cohesion, support and an inadequate parental monitoring have been all identified as antecedents of drug use in adolescence (Barnes and Farrell 1992; Butters 2002; Denton and Kampfe 1994); on the other, lack of confidence in legal authorities, negative attitude to the criminal justice system and the subsequent rejection of established social norms, enhances the likelihood of a person not following these mainstream rules (Emler and Reicher 1995), which is reflected in the adolescent period, by drug use and partaking in antisocial activities, as shown in the model.

Findings from the present study have important practical implications related to social policies on risk behaviours in adolescence. First of all, it is important to highlight that when analysing youth offending it is neither useful nor appropriate to focus only on the particular individuals involved; such a focus overlooks relevant contextual factors that need to be taken into consideration in devising policies to mitigate the problem. These policies should pay attention to social conditions in neighbourhoods and citizen-police relations, since improvement in both would have clear benefits in reducing risk behaviours in adolescence. Also intervention programmes that improve family climate and relationships with parents, as well as commitment to school and attitudes to teachers and educational institutions would be of benefit.

Finally, and despite the contributions of this paper, the following limitations related to the design of the study must also be mentioned. The use of self-reported data may create vulnerability to bias responses that could impact the validity and generalisability of the findings. However, as several authors have recently stressed, the reliability and validity of adolescents' self-reports when measuring risk behaviours such as antisocial and offending behaviour is acceptable (Flisher et al. 2004; Ritakallio et al. 2005). It should also be noted that as the data are cross-sectional, caution is necessary in making causal inferences. Findings from the current study do contribute to our understanding of particular associations among the adolescents' perceptions of social contexts, their attitudes and risk behaviours, and may guide future research that includes other relevant factors in adolescence (such as peer influence). However, a longitudinal study would be desirable to clarify causal and bidirectional relationships among variables.

\section{References}

Arbuckle, J. L. (2005). Amos 6.0 User's Guide. Chicago: SPSS, Inc.

Arum, R., \& Beattie, I. R. (1999). High school experience and the risk of adult incarceration. Criminology, $37,515-537$.

Barnes, G. M., \& Farrell, M. P. (1992). Parental support and control as predictors of adolescent drinking, delinquency, and related problem behaviour. Journal of Marriage and the Family, 54, 763-776.

Barrera, M. J., \& Li, S. A. (1996). The relation of family support to adolescents' psychological distress and behavior problems. In G. R. Pierce, and I. G. Sarason (Eds.), Handbook of social support and the family (pp. 313-343). New York: Plenum Press. 
Barry, M. (2006). Youth offending in transition: the search for social recognition. London: Routledge.

Batista, J. M., \& Coenders, G. (2000). Modelos de ecuaciones estructurales [Structural Equation Models]. Madrid: La Muralla.

Baumrind, D. (1978). Parental disciplinary patterns and social competence in children. Youth and Society, 9 , $239-276$.

Baumrind, D. (1991). The influence of parenting style on adolescent competence and substance use. Journal of Early Adolescence, 11, 56-95.

Bentler, P., \& Wu, E. (2002). EQS 6 for windows user's guide. Encino, CA: Multivariate Software.

Brook, J., Whiteman, M., Finch, S., \& Cohen, P. (1996). Young adult drug use and delinquency: Childhood antecedents and adolescent mediators. Journal of the American Academy of Child and Adolescent Psychiatry, 35, 1584-1592.

Browne, M. W., \& Cudeck, R. (1993). Alternative ways of assessing model fit. In K. A. Bollen \& J. S. Long (Eds.), Testing Structural Equation Models (pp. 136-162). Beverly Hills, CA: Sage.

Butters, J. E. (2002). Family stressors and adolescent cannabis use: A pathway to problem use. Journal of Adolescence, 25, 645-654.

Carroll, A., Hattie, J., Durkin, K., \& Houghton, S. (2001). Goal-setting and reputation enhancement: behavioural choices among delinquent, at-risk and not at-risk adolescents. Legal and Criminological Psychology, 6, 165-184.

Carroll, A., Houghton, S., Hattie, J., \& Durkin, K. (1999). Adolescent reputation enhancement: Differentiating delinquent, nondelinquent, and at-risk youths. Journal of Child Psychology and Psychiatry, 40, 593-606.

Chaiken, J. M., \& Chaiken, M. R. (1990). Drugs and predatory crime. In M. Tonry \& J. Q. Wilson (Eds.), Drugs and crime (pp. 203-239). Chicago: University of Chicago Press.

Christenson, J., \& Taylor, G. S. (1983). The socially constructed and situational context for assessment of police services. Social Science Quarterly, 63, 264-274.

Copeland, J., Howard, J., Keogh, Y., \& Seidler, K. (2003). Patterns and correlates of alcohol and other drug use among juvenile detainees in New South Wales. Drug and Alcohol Review, 22, 15-20.

Cunneen, C., \& White, R. (2002). Juvenile justice: Youth and crime in Australia. Oxford: Oxford University Press.

Demaray, M. P., \& Malecki, C. K. (2002). The relationship between perceived social support and maladjustment for students at risk. Psychology in the Schools, 39, 305-316.

Denton, R. E., \& Kampfe, C. M. (1994). The relationship between family variables and adolescent substance abuse: a literature review. Adolescence, 29, 475-496.

Emler, N., \& Reicher, S. (1995). Adolescence and delinquency. Oxford: Blackwell.

Emler, N., \& Reicher, S. (2005). Delinquency: cause or consequence of social exclusion? In D. Abrams, J. Marques, \& M. Hogg (Eds.), The social psychology of inclusion and exclusion (pp. 211-241). Philadelphia: Psychology Press.

Emler, N., Ohana, J., \& Moscovici, S. (1987). Children's beliefs about institutional roles: a crossnational study of representations of the teacher's role. The British Journal of Educational Psychology, 57, 26-37.

Emler, N., Ohana, J., \& Dickinson, J. (1990). Children's representations of social relations. In G. Duveen \& B. Lloyd (Dirs.), Social representations and the development of knowledge (pp. 47-69). Cambridge: Cambridge University Press.

Estévez, E., Murgui, S., Moreno, D., \& Musitu, G. (2007). Estilos de comunicación familiar, actitud hacia la autoridad institucional y conducta violenta del adolescente en la escuela [Family communication styles, attitude towards institutional authority, and adolescent violent behavior at school]. Psicothema, 19, 108-113.

Flisher, A. J., Evans, J., Muller, M., \& Lombard, C. (2004). Brief report: Test-retest reliability of selfreported adolescent risk behaviour. Journal of Adolescence, 27, 207-212.

Goldstein, P. J. (1989). Drugs and crime. In N. A. Weiner \& M. E. Wolfgang (Eds.), Pathways to criminal violence (pp. 16-48). Newbury Park, CA: Sage.

Hirschi, T. (1969). Causes of delinquency. Berkeley: University of California Press.

Hurst, Y. G., \& Frank, J. (2000). How kids view cops. The nature of juvenile attitudes toward the police. Journal of Criminal Justice, 28, 189-202.

Jesen, G. F. (1969). Crime doesn't pay: Correlates of a shared misunderstanding. Social Problems, 17, $189-201$.

Leblanc, M. (1994). Family, school, delinquency and criminality, the predictive power of an elaborated social control theory for males. Criminal Behaviour and Mental Health, 4, 101-117.

Lennings, C. J., Copeland, J., \& Howard, J. (2003). Substance use patterns of young offenders and violent crime. Aggressive Behavior, 29, 414-422.

Levy, K. S. (2001). The relationship between adolescent attitudes towards authority, self-concept, and delinquency. Adolescence, 36, 333-346. 
Loeber, R. (1996). Developmental continuity, change and pathways in male juvenile problem behaviours and delinquency. In J. D. Hawkins (Ed.), Delinquency and crime: current theories (pp. 28-67). New York: Cambridge University Press.

MacDonald, R., \& Marsh, J. (2005). Disconnected youth? Growing up in poor Britain. Basingstoke: Palgrave.

McAra, L. (2004). Truancy, school exclusion and substance misuse. Edinburgh study of youth transitions and crime, number 4. Edinburgh: Centre for Law and Society, University of Edinburgh.

McAra, L., \& McVie, S. (2007). Criminal justice transitions. Edinburgh study of youth transitions and crime, number 14. Edinburgh: Centre for Law and Society, University of Edinburgh.

McCord, J., Widom, C. S., \& Crowell, N. A. (2001). Juvenile crime. Juvenile justice. Panel on juvenile crime: Prevention, treatment, and control. Washington, DC: National Academy Press.

McFadden, A., March, G., Price, B., \& Hwang, Y. (1992). A study of race and gender bias in the punishment of school children. Education and Treatment of Children, 15, 140-146.

Moffitt, T. E. (1993). Adolescence-limited and life course-persistent antisocial behaviour developmental taxonomy. Psychological Review, 100, 674-701.

Moffitt, T. E. (2006). Life-course-persistent and adolescent-limited antisocial behaviour. In D. Cicchetti \& D. J. Cohen (Eds.), Developmental Psychopathology (Risk, disorder, and adaptation, Vol. 3, pp. 385-395). New York: Wiley.

Molpeceres, M. A., Llinares, L. I., \& Bernad, J. C. (1999). Perception of formal and informal authority and delinquent behavior in adolescence: a preliminary analysis. Intervención Psicosocial, 8, 349-367.

Moncher, F. J., \& Miller, G. E. (1999). Nondelinquent youths' stealing behaviour and their perceptions of parents, school, and peers. Adolescence, 34, 577-591.

Murray, C., \& Thompson, F. (1985). The representation of authority: an adolescent viewpoint. Journal of Adolescence, 8, 217-229.

Musitu, G., Estévez, E., \& Emler, N. (2007). Adjustment problems in the family and school context, attitude towards authority, and violent behaviour at school in adolescence. Adolescence, 42, 779-794.

Pedersen, W., Mastekaasa, A., \& Wichstrom, L. (2001). Conduct problems and early cannabis initiation: a longitudinal study of gender differences. Addiction, 96, 415-431.

Proctor, L. J. (2006). Children growing up in a violent community: the role of the family. Aggression and Violent Behavior, 11, 558-576.

Pudney, S. (2002). The road to ruin? Sequences of initiation into drug use and offending by young people in Britain (Home Office Research Study 253). London: Home Office.

Reebye, P., Moretti, M. M., \& Lessard, J. C. (1995). Conduct disorder and substance use disorder: comorbidity in a clinical sample of preadolescent and adolescents. Canadian Journal of Psychiatry, 40, 313-319.

Ritakallio, M., Kaltiala-Heino, R., Kivivuori, J., \& Rimpelä, M. (2005). Brief report: Delinquent behaviour and depression in middle adolescence: a Finnish community sample. Journal of Adolescence, 28, $155-$ 159.

Robins, L. N., \& McEvoy, L. (1990). Conduct problems as predictors of substance abuse. In L. R. Robins \& M. Rutter (Eds.), Straight and devious pathways from childhood to adulthood. New York: Cambridge University Press.

Rubini, M., \& Palmonari, A. (1998). The effect of school maladjustment and membership of adolescent peergroups on the orientation to the institutional system. 6th Biennial Conference of the EARA, Budapest.

Rutter, M., Giller, M., \& Hagell, A. (1998). Antisocial behaviour by young people. Cambridge: Cambridge University Press.

Sampson, R. J. (2004a). Neighbourhood and community: Collective efficacy and community safety. New Economy, 11, 106-113.

Sampson, R. J. (2004b). Networks and neighbourhoods: The implications of connectivity for thinking about crime in the modern city. In H. McCarthy, P. Miller, \& P. Skidmore (Eds.), Network logic: who governs in an interconnected world? (pp. 157-166). London: Demos.

Scarpa, A., \& Haden, S. C. (2006). Community violence victimization and aggressive behavior: the moderating effects of coping and social support. Aggressive Behavior, 32, 502-515.

Smith, D. J. (2006). School experience and delinquency at ages 13 to 16. Edinburgh study of youth transitions and crime, number 13. Edinburgh: Centre for Law and Society, University of Edinburgh.

Stipak, B. (1979). Citizen satisfaction with urban services: Potential misuse as a performance indicator. Public Administration Review, 39, 46-52.

Tarry, H., \& Emler, N. (2007). Attitudes, values and moral reasoning as predictors of delinquency. British Journal of Developmental Psychology, 25, 169-183.

Thornberry, T. P., Lizotte, A. J., Krohn, M. D., Farnworth, M., \& Joon Jang, S. (1991). Testing interactional theory: An examination of reciprocal causal relationships among family, school, and delinquency. The Journal of Criminal Law and Criminology, 82, 3-35.

Tyler, T. (2006). Why people obey the law. Oxfordshire: Princeton University Press. 
Tyler, T. R., \& Hou, Y. (2002). Trust in the law: Encouraging public cooperation with the police and court. New York: Russell Sage.

Webster, C., MacDonald, R., \& Simpson, M. (2006). Predicting criminality? Risk factors, neighborhood influence and desistance. Youth Justice, 6, 7-22.

Wei, E. H., Loeber, R., \& White, H. R. (2004). Teasing apart the developmental associations between alcohol and marijuana use and violence. Journal of Contemporary Criminal Justice, 20, 166-183.

Weitzer, R., \& Tuch, S. A. (2004). Race and perceptions of police misconduct. Social Problems, 51, 305-325.

Wiesner, M., Kim, H. K., \& Capaldi, D. M. (2005). Developmental trajectories of offending: Validation and prediction to young adult alcohol use, drug use, and depressive symptoms. Development and Psychopathology, 17, 251-270.

Williams, J. (1989). Reducing the disproportionately high frequency of disciplinary actions against minority students: an assessment-based approach. Equity and Excellence, 24, 31-37.

Wilson, J. Q., \& Kelling, G. L. (1982). The police and neighbourhood safety. Broken windows. Atlantic Monthly, 249, 29-38. 